\title{
LOS HIJOS DE INSTAGRAM. MARKETING EDITORIAL. POESÍA Y CONSTRUCCIÓN DE NUEVOS LECTORES EN LA ERA DIGITAL
}

\author{
Remedios Sánchez García \\ Pablo Aparicio Durán \\ Universidad de Granada
}

\begin{abstract}
RESUMEN: Con la incorporación de las nuevas tecnologías en la sociedad 2.0 venimos asistiendo a la construcción de un nuevo modelo de escritor que responde a las características de la era digital que se desarrolla en torno a las redes sociales y que confronta con el modelo tradicional de escritor/lector. En el presente artículo se analiza de qué forma ha afectado al discurso la eclosión de esas redes sociales (fundamentalmente Twitter e Instagram) como medio de promoción y divulgación de esta nueva literatura, construida por jóvenes prioritariamente para jóvenes; también de qué manera el marketing editorial ha auspiciado, al margen de la crítica literaria y de la previsible evolución del canon establecido, la ampliación del mercado de lo hasta ahora considerado poético para nuevos lectores, integrantes todos ellos de la Ilamada Generación Millennial (es decir: la conformada por los nacidos a partir de 1982), que siguen con fervor a un perfil de autor cuyas obras se priorizan en la sección de poesía de librerías y suplementos literarios, pero que no responden en absoluto a las previsiones de los estudiosos del género ni a las normas de la tradición, creando una polémica sobre qué es/qué no es poesía en el siglo XXI.
\end{abstract}

PALABRAS CLAVE: generación millennial, poesía joven, redes sociales, discurso literario, siglo XXI.

\section{SONS OF INSTAGRAM. PUBLISHING MARKETING. POETRY AND THE CONSTRUCTION OF NEW READERS IN THE DIGITAL ERA}

\footnotetext{
ABSTRACT: With the so called 2.0 society's incorporation of new technologies, a new mode of reader is being constructed by the digital era and its social networks wich defies the traditional model of the reader/writer. This article deals with the precise way in which the widespread use of social networks (namely Twitter and Instagram) for promotional and divulgation purposes has affected the discourse of this new type of literature, constructed
} 
by young people for (essentially) young people. It will also take a look at the way in which publishing marketing has managed to provide a profitable space for that which until now was considered to be poetry for the young Millennial Generation (i.e. those born from 1982 onwards) only, despite both the criticism directed towards it and the predictable evolution of the established literary canon. This generation of readers/writers are relentless followers of a specific type of author whose works have been given all prominence in bookshops and literary supplements but do not comply to the norms of tradition nor the previsions of scholarly critics of the genre who are at odds with this phenomenon, resulting in a polemic about what is and what is not poetry in the $21^{\text {st }}$ century.

KEYWORDS: Millennial Generation, young poetry, social networks, literary discourse, $21^{\text {st }}$ century.

Recibido: $15 / 05 / 2019$

Aceptado: 04/09/2019

Correspondencia: Remedios Sánchez García, Universidad de Granada, Facultad de Ciencias de la Educación, Campus de Cartuja s/n. 18071 Granada. Email: reme@ugr.es.

\section{INTRODUCCIÓN NECESARIA. El DISCURSO POLIÉDRICO DE LA GENERACIÓN MILLENNIAL}

Conforme avanza el siglo XXI venimos asistiendo a la construcción y desarrollo de un nuevo discurso que responde a la realidad de la denominada "Generación millennial", que es aquella conformada por los autores nacidos a partir de 1982. Avisaba ya Bauman (2005) de que, en los últimos años, la sociedad ha evolucionado hacia una ruptura cada vez más notoria con las estructuras sociales establecidas en tiempos anteriores y eso, naturalmente, tenía que afectar a lo literario, toda vez que la literatura es un producto ideológico de la sociedad en que se produce (J. C. Rodríguez, 2002). En esa misma línea escribe Scarano que la literatura no funciona de manera autónoma:

La obra literaria es ante todo un texto de cultura, que ha dejado de lado sus aspiraciones totalizadoras, al tiempo que habilita con fuerza una directriz anclada en el fragmento de vida, en la particularidad de la experiencia, en la reivindicación de lo íntimo, como ventanas desde donde auscultar el pulso de lo social. Se trata de una matriz epistémica y discursiva que propongo denominar poéticas de lo menor [...] una "literatura menor" se caracterizaría por la desterritorialización de la lengua, la articulación de lo individual en lo político y la reformulación de los lugares de enunciación, como posiciones móviles (Scarano, 2014: 103).

Especialmente desde 2015, coincidimos con Chiappe en que, "con la pantalla como máquina de confinamiento de texto y arte, la creación literaria evoluciona bajo 
una influencia que rompe la tradición impuesta por el libro códice e, incluso, por la tradición oral, de manera brusca y rápida: se genera una nueva sintaxis" (Chiappe, 2010: s/p). Ahora bien, ¿esto es aplicable a toda la poesía joven que se escribe en España? O más claramente, ¿estamos ante una generación que -en lo poético- se mueve de manera homogénea y atendiendo a parámetros estéticos, culturales e ideológicos unitarios? Este es el problema que aborda este estudio. En nuestra opinión, que iremos desgranado conforme avance la argumentación, no. Grosso modo, encontramos dentro de los Millennial como generación sociológica, al menos dos planteamientos bien diferenciados que responden a dos maneras disímiles de entender el hecho literario y su proceso de construcción estilístico-discursiva, sobre cuya base y características aún no existe una fundamentación epistemológica clara y sobre la que procede ir arrojando algo de necesaria luz. Entre otras razones porque el estudiantado de entre 16 y 24 años los sigue y los lee con un entusiasmo no visto en los últimos treinta años, rompiendo las dinámicas y los modelos de lectura asociados a la tradición.

\section{La poesía y la generación MillenNial (entre el mercado y el MARKETING)}

El punto de partida implica definir qué es y quiénes conforman eso que se ha venido a llamar desde un punto de vista sociológico, Generación millennial, cuya cronología de nacimiento establecen diversos autores entre 1980 y 2000 aproximadamente (Strauss y Howe o Carlson, por ejemplo, se ha ocupado de la delimitación temporal). Consideramos que la mejor aproximación es la de Prensky, quien ha escrito que la integran los nacidos entre 1982 y 1994 y, quienes la conforman,

[...] constituyen la primera generación formada en los nuevos avances tecnológicos, a los que se han acostumbrado por inmersión al encontrarse, desde siempre, rodeados de ordenadores, vídeos y videojuegos, música digital, telefonía móvil y otros entretenimientos y herramientas afines. En detrimento de la lectura (en la que han invertido menos de 5.000 h.), han dedicado, en cambio, 10.000 h. a los videojuegos y 20.000 h. a la televisión, por lo cual no es exagerado considerar que la mensajería inmediata, el teléfono móvil, Internet, el correo electrónico, los juegos de ordenador... son inseparables de sus vidas (2001: 1).

Con estas características sociológicas, diferentes críticos e investigadores vaticinaron que los géneros literarios que no respondieron nunca al interés masivo del público (poesía y teatro, especialmente) tenían un futuro bastante poco alentador, pero sucedió lo imprevisto: las ventas de libros incluidos en la sección de poesía de las librerías y las grandes superficies se disparó exponencialmente.

La razón fue que los jóvenes que querían iniciarse en las lides de la creación lírica empezaron a utilizar su canal habitual de comunicación: internet. Primero fueron blogs rudimentarios, luego más elaborados, en los que colgaban sus poemas iniciáticos. A propósito de esto, Djamasbi, Siegel, y Tullis ya habían avanzado que "es una de las primeras generaciones que tienen la tecnología y el Internet desde una edad 
muy temprana -ellos son significativamente más propensos que los usuarios mayores de Internet para crear blogs, descargar música, enviar mensajes instantáneos, y jugar juegos en línea" (2010: 309).

Después vinieron Twitter, los canales de Youtube y, la principal red de proyección que ha convertido a muchos (y muchas) en una suerte de líderes de masas capaces de marcar con una imagen el modo de proceder (de comprar o de pensar) de miles de personas: Instagram. Como ha escrito Sánchez García:

La cuestión es que se convirtieron rápidamente en lo que se denomina un /una influencer, alguien que es admirado e imitado hasta límites que sólo se aplicaban hasta ahora a cantantes, actores o asimilados. Y ahí es cuando estaIla la realidad en la cara del establisment: cuando estos jóvenes buscan ocupar un espacio en el hasta ese momento reducidísimo ámbito poético (2018: 73).

Esta realidad empezó a poner nerviosos a los dueños del "capital cultural", a aquellos "poseedores de la nobleza cultural" de la que hablaba Bourdieu (1998: 23), que habían venido marcando lo que había o no que leer y a qué edades; pero sucede que, en el siglo XXI, la autoridad de la crítica estaba ya muy mermada, entre otras razones porque en demasiados momentos se había orientado más por gustos particulares, por filias y por fobias, que por parámetros académicos solventes, tal y como ha aclarado Sánchez García (2018b). Por esta razón, las opiniones vertidas en los suplementos sobre el nuevo fenómeno, fundamentadas en aquello que decía Pozuelo Yvancos (1996: 3) de que sobra ira y falta estudio, no produjeron más allá de un leve rasguño en la piel de elefante de eso que llamamos mercado que se dio cuenta rápidamente $-y$ mucho antes que los estudiosos- de que estaba ante un nuevo filón.

Lectores noveles de esta sociedad 2.0, con una formación lecto-literaria muy limitada y poco interés en la literatura canónica (seguramente porque no se ha sabido transmitir a los docentes que trabajan con este rango de edad), demandaban un producto literario que les resultase comprensible desde el punto de vista lingüístico (estructuras simples: sujeto, verbo y un complemento con un nivel de riqueza léxica francamente escaso, como ya demostró F. J. Sánchez, 2018) y que respondiese a sus intereses y emociones. Es decir, todo directo y muy simplificado. Y ésas eran exactamente las características de los escritores surgidos de las redes: jóvenes de su misma generación (con pocas excepciones, entre las que cabe citar al cantautor Marwan, autor superventas para estos lectores), que reflejaban en sus textos las preocupaciones y esa "nueva sentimentalidad" de su promoción utilizando un discurso simplificado, directo, sin ningún tipo de preocupación estilística arquitectónica en la construcción poemática, por decirlo de alguna manera. La empatía entre autores y lectores fue inmediata. Y la subida exponencial de las ventas, también. Porque el mercado sí estuvo ojo avizor a lo que estaba sucediendo e, inmediatamente, "fichó" a los escritores con mayor número de seguidores para sus editoriales, creando, incluso, colecciones ex profeso. Espasa, Penguin-Random House o Planeta, quisieron su parte de esta nueva tarta económica en torno a la literatura y no les costó demasiado esfuerzo elegir. La selección natural ya se la habían hecho las propias redes con los likes (a más likes, más difusión y más posibilidades de que la editorial la escogiera para el 
libro en papel) de los usuarios/futuros compradores del producto. Fundamentalmente, Instagram. La periodista Lorena G. Maldonado así lo confirmó en una entrevista a varios editores:

Que una comunidad fuerte siga a un escritor refuerza las posibilidades de venta del libro (...) López Celada explica que Planeta es una "editorial comercial" que busca "un público amplio", por lo que "debemos estar pendientes de qué le gusta a la gente". María Fasce, directora literaria de Alfaguara (Penguin Random House), va más allá y asegura que tener en cuenta los seguidores de un autor también es "básico para el mensaje con el que se presenta el libro": "Esta era digital permite afilar, segmentar al máximo el destinatario final", reflexiona." (...) "Las editoriales dan absoluta importancia al número de seguidores. Una cuenta popular y bien Ilevada, es decir, que mantenga coherencia con el perfil que el autor quiere vender, es un arma imparable" (Maldonado, 2016: s/p).

Para aclararnos: el mercado y el marketing se dieron la mano para dar un vuelco a "la tabla de valores" (Bordieu, 1998: 165). Ése fue el momento en que se produjo el punto de inflexión: crítica literaria y autores jóvenes que se sentían los herederos de la tradición, que la habían estudiado para formarse y desarrollar su trayectoria poética (por lo que se consideraban los sucesores legítimos -y legitimados-) empezaron a ver cómo eran desplazados de su lugar porque, como escribiera Rodríguez Gaona: "el estar dentro de este circuito consolidado es lo único que en el presente concede un estatus poético" (2010: 86). Y el circuito estaba ya roto. En ese preciso instante, parafraseando a Gil de Biedma, se dieron cuenta de que la vida iba en serio y, por lo tanto, el mercado, también, en su apuesta por autores que desarrollaban unas obras con las que rompían el modelo canonizador y que se habían creado al margen de los parámetros usuales: lectura comprensiva de la tradición para la apropiación del discurso heredado, conformación de un estilo propio reformulando lo aprehendido, escritura del poemario (no menos de dos años de escribir, romper y reescribir), envío a la editorial para su valoración y a esperar una respuesta que casi nunca era afirmativa.

Es decir, que las dificultades de los jóvenes para publicar hasta ese momento eran evidentes, pero llegaron los que nosotros denominamos "hijos de Instagram" $y$, sin seguir el proceso natural de escritura, ni siquiera tenían que llamar a la puerta de esas mismas editoriales. Eran éstas las que los buscaban. Así lo expresó Álvarez Miguel, explicando lo que muchos otros poetas al "canónico modo" (permítasenos el sintagma por lo clarificador de la expresión) no se atrevían a decir salvo en petit comité: "Lo que de verdad me importa valorar es lo que ocurre alrededor de todo este fenómeno. Por ejemplo, ¿en qué posición les deja esto al resto de poetas jóvenes?" (2017: s/p). Efectivamente: ¿en qué situación quedaban los jóvenes autores que empezaban a escribir su obra bajo el influjo de la tradición reactualizada a su momento, pero, al fin y al cabo, de una tradición que tiene unas normas, un formato y una disciplina de trabajo? Porque ya las editoriales grandes, en las que estos otros jóvenes también quieren publicar, no se iban a conformar con que se vendieran 300 ó 500 ejemplares, que hasta no hace mucho era lo habitual en los poemarios. Si exceptuamos a García Montero, Karmelo Iribarren, Benjamín Prado o 
Joaquín Sabina cuyas obras suscitan in interés mucho mayor. En el caso de Sabina, bien entendido que lo que él desarrolla es un género híbrido entre la poesía y la canción de autor, con lo que, raramente, se le ha tomado por un intruso por escribir sus sonetos Ciento volando de catorce. Seguramente al de Úbeda se le acepta atendiendo a algo que ya aclaró Bajtín:

En la afición especificadora se menospreciaron los problemas de relación y dependencia mutua entre diversas zonas de la cultura, se olvidó que las fronteras entre estas zonas no son absolutas, que en diferentes épocas estas fronteras se habían trazado de maneras diversas, no se tomó en cuenta el hecho de que la vida más intensa y productiva de la cultura se da sobre los límites de diversas zonas suyas, y no donde y cuando estas zonas se encierran en su especificidad (1989: 347).

Ni Sabina en su generación, ni Marwan, por poner un ejemplo de la nueva, afectaban directamente a la concepción de lo poético porque se les consideraba más en la línea de diversificaciones de la creatividad que se insertan en la periferia de lo literario. Los que sí preocupaban (y preocupan) son Luna Miguel, Elvira Sastre, Loreto Sesma, Patricia Benito o -salvando las evidentes distancias- Irene X, ganadora del Premio Espasa de Poesía, entre otros.

El problema se halla por tanto en el núcleo, donde, por mor de los intereses del mercado, confrontan los jóvenes que forman parte de la poesía heredera de la tradición con los hijos de Instagram surgidos al calor de las redes, porque en ese eje vertebrador se concentran autores muy diversos buscando su hueco que sigue siendo restringido. El nicho de lectores, aunque ampliado, tampoco es tan grande como el de la novela (que tiene el 90,2\% de la facturación de libros de literatura vendidos, según el Informe de Comercio Interior del Libro en España, 2018: 71), salvo en contadas excepciones. Es en ese núcleo donde se produce el epicentro del terremoto con dos estéticas teóricamente enfrentadas que se pretenden analizar desde una perspectiva única. Como si ambos grupos estuvieran haciendo lo mismo y los receptores de sus escritos respondiesen al mismo perfil de lector. Ahí, creemos, está el error capital.

\subsection{La tradición reinterpretada. Autores al hilo del canon}

La función poética del lenguaje, ya lo avisaba Jakobson (1981), exige ambigüedad y autorreflexividad, en la línea de lo ya dicho por Saussure: "los grupos formados por asociación mental no se limitan a aproximar los términos que presenten algo en común; el espíritu capta también la naturaleza de las relaciones que los unen en cada caso y crea, con eso, tantas series asociativas como relaciones diversas existan (1945: 145). También defiende Eco, la misma postura: "el receptor es Ilevado no solamente a individualizar para cada significante un significado, sino a demorarse sobre el conjunto de los significantes (en esta fase elemental: los degusta como hechos sonoros, les da una intención como 'materia agradable'" (1984: 79). Es decir, exactamente lo contrario de lo que se aplica en los textos de los Instagramers pero que sí emplean los autores que escriben al hilo del canon. 
En los últimos años, los jóvenes poetas que buscan abrirse un hueco han intentado seguir haciendo su trabajo. Jorge Villalobos, Rosa Berbel, Estefanía Cabello, Virginia Navalón, (por poner cuatro ejemplos) han continuado la fórmula de la tradición con una notoria calidad a pesar de estar iniciando su andadura. Su perspectiva del canon (entendido como "selección representativa de la estética de un momento determinado", Sánchez García, 2015: 9) es plural y ellos han sabido rehacerlo, como corresponde a los autores de cada tiempo.

Ninguno de estos cuatro autores ha manifestado la más leve beligerancia pública (que conozcamos) hacia estos otros vinculados a las redes. Parecen ser conscientes de la evidencia: que se dirigen a públicos distintos en edad e intereses. Tampoco la actitud del mercado es la misma ante ellos incluso, con lo que lo que pudiera afectar a lo que se denomina "valor literario" entendido como "el verdadero espacio donde se realizan las variantes ideológicas de la Norma o como el sismógrafo de las variantes sociales del campo (J. C. Rodríguez, 2002: 56). El valor literario en estos casos es notorio pero el interés del mercado muy limitado, en consonancia con lo que ha sido siempre el género.

\subsection{Las voces que surgieron de las redes. Autores que vienen de internet}

La situación contraria la tienen quienes han utilizado las redes como herramienta de construcción poemática y promoción. Por poner otros cuatro ejemplos, valgan los de Elvira Sastre, Loreto Sesma, Patricia Benito, Srta. Babi y, marcando esa abismal distancia, Irene X. Pozo ya avisó de que "Se dicen poetas y tienen un mercado que es envidia de muchos otros autores. Sin embargo, su lenguaje es criticado por críticos y autores -otros incluso prefieren no prestar atención al fenómeno- por simple, mercantilista y en ocasiones oportunista" (Pozo, 2018: s/p).

Más razón entendemos que tiene Morales Lomas cuando escribe que

Es el otro quien ha reconocido su obra y la ha hecho suya, se ha identificado con ella y quien ha llevado su esfera privada a la esfera social y pública. Si existen miles de personas en todo el mundo que reconocen estos poemas es porque estas miles de personas forman parte de una comunidad de pensamiento, de sentimiento. La poesía nace como un acto de solidaridad, de alteridad y de convivencia. Se acaba convirtiendo, como decía Kant, en la Crítica del juicio en un símbolo moral. Estas poetas han comprendido, como enuncia Foucault en Hermenéutica del sujeto (1994), que no se puede mirar uno a sí mismo sin ver a los demás, porque, como diría el autor francés, el otro es indispensable en la práctica de uno mismo (Morales Lomas, 2018: 45).

Porque no estamos hablando de calidad literaria (eso es otro tema bien distinto al que nos ocupa). Estamos hablando de lectores masivos en la era en que, supuestamente, los libros en papel habían dejado de tener interés para nuestros jóvenes. Y se constata que nos habíamos equivocado. 


\section{LO QUE DICEN LOS LECTORES (O CÓMO INTEGRAR LOS NUEVOS MODELOS ¿LITERARIOS?)}

Primera cuestión que hay que tomar en consideración: ¿cómo es el nuevo lector millennial? La respuesta la daba Isabel Solé hace algún tiempo:

la revolución tecnológica que estamos viviendo en las últimas décadas ha provocado la informatización del texto impreso y abre paso a una nueva forma de ser lector, el que construye su propio texto; navegando por la red, a través de los webs, chats, blogs, etc., el lector construye su propia ruta y no se limita a seguir la que fue marcada por autores con frecuencia desaparecidos o, como mínimo, desconocidos (2012: 48).

Con esta base, ya podemos afrontar la siguiente pregunta: ¿qué buscan estos lectores novísimos en un texto? Ya lo explicó Sánchez García hace unos meses:

Pues no la poesía al canónico modo (la que se enseña en las aulas de Educación Secundaria y que abarca de las jarchas a la literatura de los años 80), sino la poesía escrita por autores de su misma generación que, además debe cumplir otro parámetro: estar escrita por alguien reconocible en internet; su autor ha tenido como motor de proyección y difusión las redes sociales que son, al fin y al cabo, la herramienta capital con la que aprenden y se relacionan la mayoría de los jóvenes de hoy (2018a: 73).

Esto que dicen los lectores se interpreta a través del Informe del Comercio Interior del Libro en España que constata que, en 2016, la venta de poesía ha subido un 2,6\% (2016: 62), unas cifras a las que ya se refirió también Unai Velasco en un artículo sobre el nuevo fenómeno (2017: s/p) cuestionando la legitimidad -en términos literarios- de los autores nacidos de las redes. En 2017, el mismo informe señala que ha subido la edición de poesía un 1,1\%, es decir, 985 títulos publicados en poesía-teatro (se evalúan juntos), con una variación interanual de 6,3\% (2018: 39). Una cantidad ridícula en el cómputo global pero muy considerable si tenemos en cuenta la especificidad hasta ahora de su receptor que, normalmente, leía poesía por pura obligación académica pero que, por mor de la influencia de las redes sociales ha empezado a interesarse y a buscar poesía por su cuenta y riesgo. Asumámoslo. Petrucci ya avanzó lo que hoy sucede:

la constatación del neoanalfabetismo de una buena parte de la población joven o adulta, un neoanalfabetismo definido de muy diferentes maneras, pero del que también se responsabiliza, al menos en parte, a una escuela que, se dice, ha fracasado en el cumplimiento de su objetivo fundamental: el aprendizaje de la lectura, la escritura y el cálculo. El otro, la irrupción de nuevos lenguajes. No sólo de los audiovisuales, sino también de los informáticos $-y$, con ellos, de la videoescritura- y de los generados por una serie de medios o soportes -cómic, publicidad-cuya principal característica es la ausencia de un canon gráfico y, en el segundo caso, una escritura hecha más para ser vista que para ser leída (1987: 70).

La misión de críticos literarios y docentes es revertir esta situación, empezando por asumir nuestra propia realidad, de la que ya se ocupó Sánchez García: "Si vivi- 
mos un tiempo en que la poesía debe reconquistar su crédito, no lo es menos que la crítica literaria, también. Ergo, la conclusión primera es que la poesía (como creación y como objeto de estudio riguroso) tiene que recuperar el prestigio perdido" (Sánchez García, 2018b: 84). Una vez que tengamos claro el problema de partida podremos ir recuperando la importancia de la "aculturación" mediante lo literario implementando propuestas didácticas que respondan a las necesidades académicas pero también a los intereses y gustos del alumnado. En 2010 ya lo expuso Borràs Castanyer:

la aparición de distintas herramientas que los creadores utilizan con una finalidad artística está reconfigurando sus prácticas artísticas, a la vez que nuestros hábitos de lectura que, progresivamente, se adaptan a la nueva realidad. En su viaje de la página impresa hacia la pantalla [...] la literatura ha experimentado un cambio en la forma que debemos evaluar hasta qué punto también comporta un cambio del contenido y, consecuentemente, de nuestro modo de lectura... (2011: 61).

Una vez que seamos conscientes de que las prácticas de lectura de la nueva generación han cambiado -porque la sociedad evoluciona y los modelos de lector también- podremos afrontar la realidad de construcción/deconstrucción del canon para reformular, desde lo académico, aquello que el mercado se obstina en imponer.

\section{Conclusiones}

La poesía, como decía Meschonnic (2001) es algo difuso y esa ambigüedad en los últimos tiempos ha propiciado la desestabilización en cuanto al sentido del género, a lo que implicaba hasta ahora. La neoliteratura que surge al calor de Instagram es un fenómeno de masas que ha roto las jerarquías y la dinámica público/privado a las que se refería Juan Carlos Rodríguez (2002) convirtiendo la vida privada en foco argumental por su carácter confesional, con lo que se propicia que quien lee y quien habla puedan identificarse totalmente porque comparten el discurso y la emoción sin ningún tipo de fingimiento ni de construcción de un personaje poemático. Incluso, interactúan a través de las redes. Thomas Harris habla de "una nueva mirada sobre el orden acostumbrado del lenguaje y el mundo poetizado" (2002: 307). Se escribe en redes y, si funciona atendiendo a los followers, a esos jóvenes que "han crecido en un mundo digital y esperan utilizar estas herramientas para sus entornos avanzados de aprendizaje" (Bajt, 2011: 54), acaba publicándoseles sus textos en un libro con tiradas de miles de ejemplares que desaparecen con rapidez de los estantes a pesar de que la crítica los considere carentes de calidad alguna u otra cosa (subprosa, lo denomina Rivero Taravillo, 2018: s/p: "por ser meros renglones cortados arbitrariamente sin la calidad de una prosa cuidada) brillan por su ausencia el ritmo, el conocimiento de la tradición, la arquitectura versal o estrófica, la elipsis, la contención, el vuelo metafórico, la observación de la naturalidad, la reflexión". Como parapoesía lo entiende Luis Alberto de Cuenca (en Bravo, 2017: s/p) diferente al género poético como se ha entendido a lo largo del tiempo.

Al final, la cuestión anda cerca de aquello que avanzaron Lipovesky y Serroy de que "en el capitalismo artístico tardío 'todos somos artistas"” (2015: 68), provocando 
un absoluto desconcierto en los que ya hemos Ilamado "autores al canónico modo" y, singularmente en la crítica que ha seguido al mercado y ha aceptado (ha asumido sin más esta clasificación) sin pararse a pensar en que no estamos hablando de la misma cosa, sino que lo que hacen esos jóvenes que desarrollan su creatividad en Instagram (los que tienen algo de calidad, obviamente) es otro subgénero hasta ahora poco frecuentado y que puede tener cierto interés en las aulas: el de la poesía juvenil, que hasta ahora había estado centrado en la narrativa, como ya valoró García Padrino: "Este fenómeno (el de la literatura juvenil), a caballo entre lo económico y lo sociológico, se ha proyectado de modo casi exclusivo en la narrativa. En las colecciones hoy tan en auge apenas se contempla la presencia de poesía" (1998: 107). La adscripción a este subgénero la hizo, casi al principio de la polémica Fernando Valverde en una reflexión que compartimos:

Es cierto que resulta a veces complicado reconocer como poesía una parte del trabajo de los jóvenes que se han dado a conocer en las redes sociales. Tal vez porque no se trata de poesía a secas, sino de Poesía Juvenil, un género que no había sido explotado y que ahora ha surgido con mucha fuerza. Así como existe la poesía infantil, que no es otra cosa que poesía escrita para el lector infantil, existe una poesía juvenil, que hace estragos entre los jóvenes y que se ha convertido en un gran fenómeno de ventas. Querer analizar la poesía infantil o la poesía juvenil desde la perspectiva de la poesía es tan injusto como equivocado (2017: s/p).

Por eso, no ha lugar entre unos y otros esa "pugna por la hegemonía" de la que hablaba J. C. Mainer: "en la literatura, casi todo es contienda, porque siempre está de fondo la constitución de un mercado literario" (1998: 11). La rivalidad es responsabilidad exclusiva de un mercado que ha denominado poesía, sin ningún adjetivo calificativo a lo que hacen los instagramers, creando una situación de confusión que le resulta más que conveniente y que pone en un brete al docente de educación secundaria que debe dar respuesta a las preguntas de sus alumnos/lectores cuando, en clase, tiene que dar respuesta a un fenómeno que poco tiene que ver con la poesía de Garcilaso, Bécquer o Machado ni con los contenidos curriculares del área de Lengua y Literatura. Obviamente: estamos hablando de otra cosa, cercana al bestseller que encarnan en novela las obras Ruiz Zafón o María Dueñas que no tienen que ser denostados per se, porque también es un bestseller El Quijote o Veinte poemas de amor y una canción desesperada de Neruda y eso no lo convierte en mala literatura canónica. La cuestión es que el lector/consumidor gustoso de estos textos es otro al habitual de la lírica y lo que busca en estas otras composiciones es bien diferente que lo que le pueden aportar las mentadas obras. Creemos que la clave reside en lo que ya expuso Sánchez García:

se dirigen a públicos distintos en edad e intereses. En términos del circuito de la comunicación, podríamos decir que ni el perfil de emisor es el mismo, ni el canal funciona de la misma manera (así lo afirmaba F. Valverde, en una conferencia reciente de 2018), los mensajes que transmiten tienen poco que ver en lo formal (una, busca la claridad en mayor o menor grado; otra, juega con el lenguaje y sus recursos) y tampoco el receptor busca lo mismo en unos que en otros. Porque, repito: son receptores diferentes. Si lo trasladamos a otra 
época, es como si quisiéramos que, quien leía con gusto a Catulo, leyese con igual entusiasmo a Campoamor. Si entonces, con las condiciones socioeconómicas decimonónicas, había lectores para ambos (más para Campoamor que para Catulo, conste), ahora, en la era digital y a golpe de clic, se me antoja que es obvio que infinitamente más (2018a: 71).

Es, tal vez el justo término medio que reconduce la legitimación del mercado que no ha sabido frenar la crítica, tan preocupada en su conjunto de negar la mayor: que fuese literatura en modo alguno. Es necesario encontrar un sendero que permita ubicar tanto a estos escritores que han erigido una trayectoria (sea o no con pies de barro, el tiempo lo dirá), como a sus lectores militantes de una religión que no comprendemos porque, lisa y llanamente, escapa a lo hasta ahora conocido y entendido como poesía, con sus exigencias y sus características definitorias. Si no, no cabe otra que acudir a Blanchot cuando, creemos que con acierto avisaba de que "la esencia de la literatura consiste en escapar a toda determinación esencial, a toda afirmación que la estabilice o realice: ella nunca está ya aquí, siempre hay que encontrarla o inventarla de nuevo" (1969: 225). En ese reinventar constante, en ese trabajar permanente al modo de Sísifo, está la tarea del docente comprometido con hacer de la lectura una tarea satisfactoria y gratificante sin perder de vista que en la sociedad actual las herramientas digitales son el modo natural de interrelación de nuestros discentes y que, por mucho que lo neguemos, los hijos de Instagram no entienden el mundo ( y por ende, la literatura) al margen de las redes y todo lo que ellas conllevan de modernidad, de cambio, de perversión del sistema, de confusión entre lo que son/no son las cosas, incluida la literatura, tan manoseada por el mercado y tan condicionada por el marketing editorial. Pero, también de democratización de la cultura plural en constante proceso de reinterpretación para ajustarla al momento histórico en que se produce.

\section{ReFERENCIAS BIBLIOGRÁFICAS}

Álvarez Miguel, D. (2017). Tras el boom de los nuevos poetas, llega la poesía. Oculta Lit. Revista de literatura, 12 de enero de 2017. Recuperado de http://www.ocultalit. com/opinion/poesia-nuevos-poetas/

Bajt, S. K. (2011). Web 2.0 Technologies: Applications for Community Colleges. Wiley Periodicals, 154, pp. 53-62.

Bajtín, M. (1989). Respuesta a la pregunta hecha por la revista Novy Mir. En Estética de la creación verbal. México: Siglo XXI.

Bauman, Z. (2005). Modernidad líquida. Buenos Aires: Fondo de Cultura Económica.

Blanchot, M. (1969). La desaparición de la literatura. En El libro que vendrá. Caracas: Monte Ávila.

Bordieu, P. (1998). La distinción. Criterios y bases sociales del gusto. Madrid: Taurus.

Borràs Castanyer, L. (2011). Nuevos lectores, nuevos modos de lectura en la era digital. En VV. AA. Literatura e internet. Nuevos textos, nuevos lectores (pp. 41-66). Málaga: AEDILE. 
Bravo, E. (2017). Parapoesía, parapoetas y los límites que no debemos cruzar. ¡Ah! Magazine. Recuperado de http://www.ahmagazine.es/parapoesia-parapoetas-ylos-limites-que-no-debemos-cruzar/

Carlson, M. (2008). The Lucky Few: Between the Greatest Generation and the Baby Boom. Nueva York: Springer.

Chiappe, D. (2010). Ciudad de letras danzantes. Recuperado de http://domenicochiappe.com/ciudad_letras_danzantes.pdf

Djamasbi, S., Siegel, M. y Tullis, T. (2010). Generation Y, web design, and eye tracking. International Journal of Human-Computer Studies, 60, 307-323.

Eco, U. (1984). La obra abierta. Barcelona: Planeta.

Federación de Gremios de Editores de España. (2017). Informe del Comercio Interior del Libro en España 2016. Madrid: Federación de Gremios de Editores de España.

Federación de Gremios de Editores de España. (2018). Informe del Comercio Interior del Libro en España 2017. Madrid: Federación de Gremios de Editores de España.

García Padrino, J. (1998). Vuelve la polémica: ¿existe la literatura...juvenil? Revista interuniversitaria de formación del profesorado, 31, 101-110.

Harris, T. (2002). La voz de los 80 (promociones poéticas 1979-1989). En K. Kohut y J. Saravia (Eds.), Literatura chilena hoy. La difícil transición. Madrid: Iberoamericana Vervuert.

Howe, N. y Strauss W. (2000). Millennials Rising: The Next Great Generation: The Next Great Generation. Nueva York: Vintage Books.

Jakobson, R. (1981). Ensayos de lingüística general. Barcelona: Seix Barral.

Lipovesky, G. y Serroy, J. (2015). La estetización del mundo. Vivir en la época del capitalismo artístico. Barcelona: Anagrama, pp. 31-107.

Mainer, J. C. (1998). Para otra antología. En J. C. Mainer, El último tercio del siglo (1968-1998). Antología consultada de la poesía española (pp. 9-50). Madrid: Visor.

Maldonado, L. (2017). Literatura 'follow': tantos seguidores tienes, tanto vales. El Español, 27/01/2016. Recuperado de https://www.elespanol.com/cultura/ libros/20160126/97490295_0.html

Meschonnic, H. (2001). Célébration de la poésie. París: Seuil.

Morales Lomas, F. (2018). Subjetividad y humanidad en jóvenes poetas actuales. Hacia un nuevo paradigma. En R. Sánchez García (Coord.), Nuevas poéticas y redes sociales. Joven poesía española en la era digital (pp. 31-48). Madrid: Siglo XXI.

Petrucci, A. (1987). Scrivere e no. Politiche della scritura e analfabetismo nel mondo d'oggi. Roma: Editori Riuniti. 
Pozo, E. G. (2018). Poesía en tiempos de instagram: entre el fenómeno groupie y los hachazos de la crítica. Cadena Ser. Recuperado de http://cadenaser.com/ ser/2018/07/15/cultura/1531668048_207205.html. 15/7/2018

Pozuelo Yvancos, J. M. (1996). Canon: estética o pedagogía. Ínsula, 600, 3-4.

Prensky, M. (2001). Digital natives, digital immigrants, Part 1. On the Horizon, 9(5), 1-6.

Rivero Taravillo, A. (2019). La falsa nueva poesía. Acercamiento crítico a un fenómeno literario. República de las Letras. Recuperado de https://republicadelasletras. acescritores.com/2019/03/05/la-falsa-nueva-poesia-un-acercamiento-critico-a-lapoesia-en-las-redes/

Rodríguez, J. C. (2002). De qué hablamos cuando hablamos de literatura. Granada: Comares.

Rodríguez-Gaona, M. (2010). Mejorando lo presente. Poesía española última: posmodernidad, humanismo y redes. Barcelona: Caballo de Troya.

Sánchez García, F. J. (2018). Análisis de la riqueza léxica de los poetas millennial. Primera aproximación. En R. Sánchez García (Coord.), Nuevas poéticas y redes sociales. Joven poesía española en la era digital (pp. 175-186). Madrid: Siglo XXI.

Sánchez García, R. (2015). El canon abierto. Última poesía en español. Madrid: Visor.

Sánchez García, R. (2018a). Joven poesía, mercado literario y redes sociales (o cómo tenderle una trampa a los géneros literarios). En R. Sánchez García (Coord.), Nuevas poéticas y redes sociales. Joven poesía española en la era digital (pp. 65-80). Madrid: Siglo XXI.

Sánchez García, R. (2018b). Así que pasen treinta años. Historia interna de la poesía española. Madrid: Akal.

Saussure, F. (1945). Curso de lingüística general. Buenos Aires: Losada

Scarano, L. (2015). Poéticas de lo menor en el hispanismo transatlántico. El taco en la brea, 1(2), 164-195. Recuperado de https://doi.org/10.14409/tb.v1i2.4677.

Solé, I. (2012). Competencia lectora y aprendizaje. Revista Iberoamericana de Educación, 59(1), 43-61.

Valverde, F. (2017). También son poetas. Sobre el boom de la poesía juvenil. Oculta Lit, 17/1/ 2017. Recuperado de https://www.ocultalit.com/poesia/poesia-juvenil/

Velasco, U. (2017). 50 kilos de adolescencia, 200 gramos de Internet (I). CTXT, 14/1/2017. Recuperado de http://ctxt.es/es/20170118/Culturas/10723/boom-jovenes-poetas-elvira-sastre-poesia-de-la-experiencia.htm 